\title{
Differences and influencing factors related to underground water carbon uptake by karsts in the Houzhai Basin, southwestern China
}

\author{
Junyi Zhang ${ }^{1,2}$, Zihao Bian ${ }^{1}$, Minghong Dai ${ }^{1}$, Lachun Wang ${ }^{1}$, Chunfen Zeng ${ }^{1}$, and Weici Su ${ }^{3}$ \\ ${ }^{1}$ School of Geographic and Oceanographic Sciences, Nanjing University, Nanjing 210023, China \\ ${ }^{2}$ School of Tourism and Land Resources, Chongqing Technology and Business University, Chongqing 400067, China \\ ${ }^{3}$ The Institute of Mountain Resources, Guizhou Academy of Sciences, Guiyang 550018, China \\ Correspondence to: Chunfen Zeng (zengchunfen@nju.edu.cn) and Lachun Wang (wang6312@263.net.cn)
}

Received: 26 February 2016 - Published in Solid Earth Discuss.: 10 March 2016

Revised: 19 July 2016 - Accepted: 28 July 2016 - Published: 25 August 2016

\begin{abstract}
Carbon sink in karstic areas is very important at a global scale. Consequently, accurate determination of the carbon sink of karst ecosystems has become a core issue in research. We used flow and carbon ion concentration data from three stations with different environmental background conditions in the Houzhai Basin, southwestern China, to analyse the differences in carbon uptake between stations and to determine their impact factors. The results show that carbon sink discharge was mainly controlled by the flow at each site. Preliminary analysis indicated that the rapid increase in flow only had a partial dilution effect on the ion concentrations due to the high speed and stability of chemical carbonate weathering. The Land-Use and Cover-Change (LUCC) type had important effects on the bicarbonate ion concentrations; under stable run-off conditions, the influence of flow variation on the ion concentration was lower than the effects of chemical carbonate weathering on bicarbonate ion concentrations under different environmental conditions (a comparison of Laoheitan and Liugu stations showed a difference of $150 \%$ ). However, if run-off increased significantly, the impact of run-off variation on bicarbonate ions was greater than the effects of chemical carbonate weathering caused under different environmental conditions. This work provides a reference for the calculation of the karst geological carbon sink.
\end{abstract}

\section{Introduction}

Global warming caused by the emissions of greenhouse gases has become one of the core areas of environmental change research. One of the most pressing concerns in the science of global climate change is the effective accounting of atmospheric $\mathrm{CO}_{2}$ in the global budget (Schindler, 1999; Melnikov and Neill, 2006; Liu et al., 2010; Kao et al., 2014). In order to control global warming, it is necessary to control emissions of carbon dioxide through carbon capture and storage (CCS) technology. In addition to developing CCS technology, an understanding of a number of natural ecological and geological processes such as rock weathering, plant growth, and other physical, chemical, and biological processes can also improve CCS processes (Hoffmann et al., 2013). Carbonate weathering in rock weathering processes is considered to be both an important source and sink of $\mathrm{CO}_{2}$ (Zeng et al., 2015; Lian et al., 2011; Liu and Zhao, 2000; Serrano-Ortiz et al., 2010; James et al., 2006). Carbonate rock dissolves more easily in water in which $\mathrm{CO}_{2}$ is dissolved, and at a temperature of $15^{\circ} \mathrm{C}$ and atmospheric $\mathrm{CO}_{2}$ partial pressure of $380 \mathrm{ppmv}$, the equilibrium concentration of dissolved inorganic carbon (DIC) in a water system of $\mathrm{CaCO}_{3}-\mathrm{CO}_{2}-\mathrm{H}_{2} \mathrm{O}$ can reach $1231 \mathrm{~mol} \mathrm{~L}^{-1}$ in water with calcium carbonate (Dreybolt, 1988). Moreover, karst is widely distributed around the Earth; it occupies approximately $11.2 \%$ of the Earth's surface and approximately 15 million $\mathrm{km}^{2}$ over the earth (Dürr et al., 2005). Therefore, carbonate rock is closely associated with atmospheric $\mathrm{CO}_{2}$ concentrations through carbonate weathering processes, and has become an important component of the global carbon 


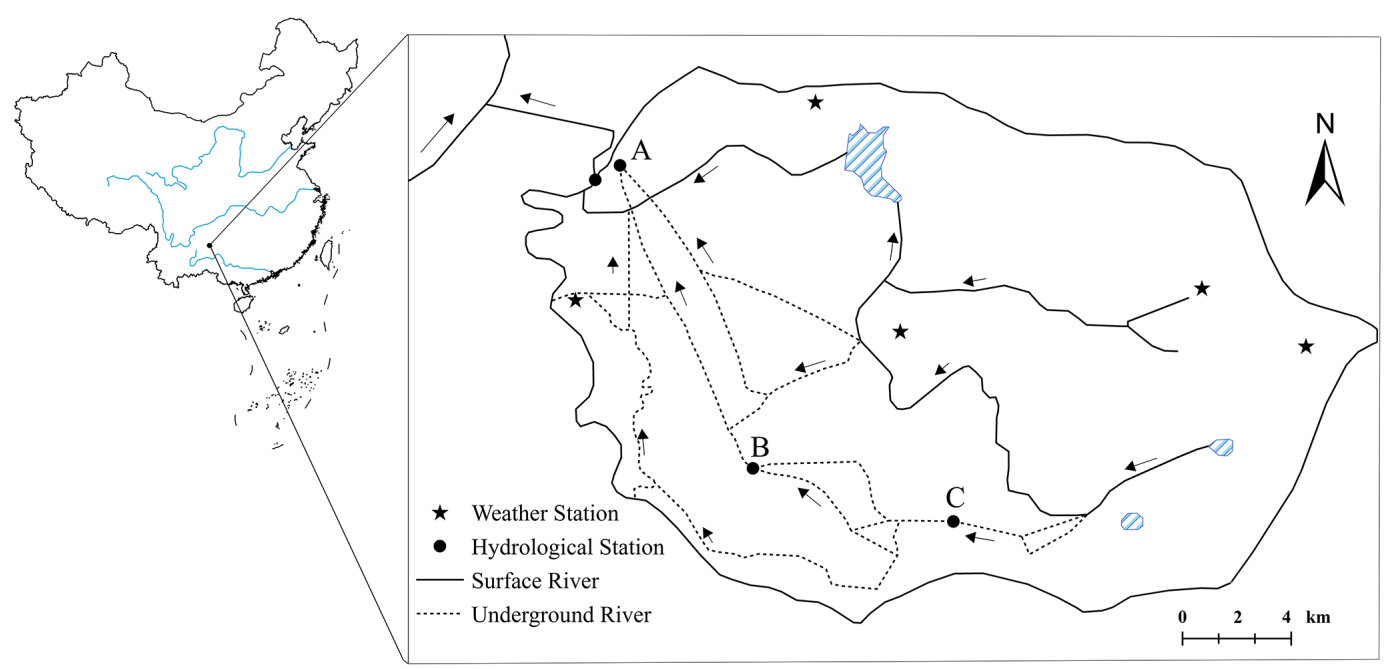

Figure 1. The distribution of drainage systems and weather hydrological stations.

Table 1. The proportion of different land cover types and characteristics of underground river chemicals in the west and east banks of Dagou River.

\begin{tabular}{lrrrrrrr}
\hline Region & $\begin{array}{r}\text { Forest } \\
\text { land (\%) }\end{array}$ & $\begin{array}{r}\text { Arable } \\
\text { land (\%) }\end{array}$ & $\begin{array}{r}\text { Bare } \\
\text { rock }(\%)\end{array}$ & $\begin{array}{r}\text { Barren } \\
\text { land }(\%)\end{array}$ & $\begin{array}{r}\mathrm{HCO}_{3}^{-} \\
\left(\mathrm{mg} \mathrm{L}^{-1}\right)\end{array}$ & $\begin{array}{r}\mathrm{PCO}_{2} \\
(\mathrm{~Pa})\end{array}$ & $\begin{array}{r}\text { Carbon sink } \\
\left(\mathrm{t} \mathrm{km}^{-2} \mathrm{yr}^{-1}\right)\end{array}$ \\
\hline $\begin{array}{l}\text { The west bank } \\
\text { of Dagou River } \\
\begin{array}{l}\text { The east bank } \\
\text { of Dagou River }\end{array}\end{array}$ & 56.13 & 15.15 & 14.1 & 10.98 & 233.71 & 909.46 & 45.67 \\
\hline
\end{tabular}

cycle. As a result, carbon uptake from chemical weathering has significantly conditioned the evolution of atmospheric $\mathrm{CO}_{2}$ concentrations in the long (over the past 100 million years; Berner et al., 1983) and short term. Moreover, previous research has shown that more carbon is sequestered from carbonate weathering than from silicate rock weathering (Liu, 2012). The problems associated with karst dissolved inorganic carbon (DIC) reprecipitation occur on geological timescales. Existing studies have shown that karst aquatic organisms can convert DIC into organic carbon (OC); consequently, carbonate weathering has stable carbon sink effects on a long timescale (Chen et al., 2014; Liu, 2012). Moreover, the carbon sink intensity is 51 times higher than that of the ocean biological pump (Passow and Carlson, 2012; Chen et al., 2014). This shows that DIC used in photosynthesis of aquatic organisms has important carbon sink effects in water. In addition, it also implies that DIC can produce stable carbon sinks in karst areas.

Consequently, it is very important to accurately estimate net carbon uptake from carbonate weathering processes. Currently, there are two main methods for calculating carbonate weathering carbon sinks. The first method uses the empirical relationship between carbon uptake rates and different lithology types, and calculates the intensity of weathering by determining different empirical dissolved constants, such as 0.0294 and $0.0383 \mathrm{~g} \mathrm{C} \mathrm{mm}^{-1}$, as estimated by AmiotteSuchet and Probst (1993) and Bluth and Kump (1994), respectively. The other method estimates carbon sinks using observations of river chemistry such as karst water flow and concentrations of bicarbonate. Nevertheless, there are always some differences between the results of the two calculation methods (Yan et al., 2011).

The intensity of karst carbon sink is influenced by different factors, such as vegetation type, temperature, and aquatic microorganisms (Hagedorn and Cartwright, 2009). Carbon sink can differ by more than $14 \%$ under different land cover types (Table 1; Qin et al., 2011). There is a significant correlation between temperature and $\mathrm{CO}_{2}$ concentration in soil layers 20 and $50 \mathrm{~cm}$ deep in the Wangpai mountain of the Maolan conservation area (Wan, 1995), and the mechanism and intensity of soil $\mathrm{CO}_{2}$ are closely related to the habitat of the soil. However, there was no significant correlation between temperature change and carbon sink flux (Yu et al., 2015). This may have occurred because the temporal resolution effects did not match those of the temperature and carbon sink changes or changes in the "biological pump" of aquatic organisms caused by changes in light and temperature. A significant correlation between the biomass of aquatic organisms and 
Table 2. The highest and lowest ion concentration in the wet season, dry season, and throughout the whole year for the LHT station 19882002.

\begin{tabular}{lrr|rrr|rrr}
\hline & \multicolumn{7}{c}{ LHT ion concentration $\left(\mathrm{mg} \mathrm{L}^{-1}\right)$} \\
\cline { 2 - 9 } & Highest & Lowest & & Highest & Lowest & & Highest & Lowest \\
\hline Wet & 240.5 & 201.7 & Dry & 259.6 & 234.7 & Whole & 248.3 & 218.8 \\
Season & $(1994)$ & $(1999)$ & Season & $(2002)$ & $(1991)$ & Year & $(1994)$ & $(1999)$ \\
\hline
\end{tabular}

Table 3. Standard deviation of production flow, ion concentration, and carbon sink for each station in the dry and wet seasons and over the whole year.

\begin{tabular}{lccc|rcc|ccc}
\hline & \multicolumn{3}{c|}{$\begin{array}{c}\text { Water discharge } \\
\text { rate }\left(\mathrm{m}^{3} \mathrm{~s}^{-1}\right)\end{array}$} & \multicolumn{3}{c|}{$\begin{array}{c}\text { Bicarbonate } \\
\text { concentration }\left(\mathrm{mg} \mathrm{L}^{-1}\right)\end{array}$} & \multicolumn{3}{c}{$\begin{array}{c}\text { Carbon uptake } \\
\left(\mathrm{g} \mathrm{C} \mathrm{yr}^{-1}\right)\end{array}$} \\
\cline { 2 - 10 } Station & Wet & Dry & Year & Wet & Dry & Year & Wet & Dry & Year \\
\hline Maoshuikeng & 0.108 & 0.109 & 0.060 & 6.46 & 6.64 & 5.26 & 1.12 & 0.84 & 0.43 \\
Liugu & 0.109 & 0.015 & 0.051 & 10.64 & 4.81 & 4.99 & 2.93 & 0.45 & 1.54 \\
Laoheitan & 0.073 & 0.061 & 0.045 & 10.04 & 8.41 & 7.55 & 3.34 & 1.84 & 2.05 \\
\hline
\end{tabular}

their DIC utilization has been reported, and the change in $\delta^{13}$ DIC in a few submerged plant environments was much smaller than in the large number of submerged plant growth environments. However, the change in $\delta^{13}$ DIC was mainly influenced by changes in the metabolism of aquatic plants during the day and at night (Chen et al., 2014).

Karst is widely distributed in China, which has approximately 3.44 million $\mathrm{km}^{2}$ of karst area, including buried, covered, and exposed carbonate rock areas (Jiang et al., 2014), and about 0.4 million $\mathrm{km}^{2}$ of karst is located in southwestern China (Jiang and Yuan, 1999). The most frequently used calculation method for carbon sequestration is the forward method (Zhang, 2011) and, in China's karst regions, the river chemistry method (Yan et al., 2011; Zhao et al., 2010; Jiang et al., 1999). However, there are some defects in the forward method because physical models cannot truly reflect the in situ karstification and carbon migration process (Kang et al., 2011); consequently, the river chemistry method is more frequently adopted (Zhao et al., 2010; Yan et al., 2012; Zhang et al., 2015; Huang et al., 2015). There are large discrepancies in the estimates of carbon sequestration in China, ranging from $5 \mathrm{Tg} \mathrm{Cyr}^{-1}$ (Jiang and Yuan, 1999) to $12 \mathrm{Tg} \mathrm{C} \mathrm{yr}^{-1}$ (Yan et al., 2011) and $18 \mathrm{Tg} \mathrm{C} \mathrm{yr}^{-1}$ (Liu and Zhao, 2000). These values are usually derived from the observed carbon discharge from a single water chemical observatory in a single basin in southwestern China. However, there may be some deviations in the results of this single observation site because of the high heterogeneity of the karst system, the sensitivity of the response to external environment changes, and the interference of human activity, which is usually intensified in karst regions (Yuan, 1997; Jiang et al., 2014; Zhang et al., 2016). Studies have shown that carbonate weathering is sensitive to ecosystem dynamics, which means that carbonate weathering and associated $\mathrm{CO}_{2}$ con- sumption discharges quickly react to any global changes or land-use modifications (Calmels et al., 2014). Therefore, in this study, we used flow and carbon ion concentration data from three observation stations with different environmental background conditions in the same karst groundwater basin in order to analyse the differences in carbon uptake between stations and their impact factors. This work also provides a reference for improving the calculation accuracy of the karst geological carbon sink.

\section{Materials and methods}

\subsection{Study area}

Houzhai Basin is located in Puding county in the middle of Guizhou province $\left(26^{\circ} 13^{\prime}-26^{\circ} 15^{\prime} \mathrm{N}, 105^{\circ} 41^{\prime} 105^{\circ} 43^{\prime} \mathrm{E}\right)$, southwestern China. The total area of the basin is $80.65 \mathrm{~km}^{2}$, and the length of the main river is approximately $12 \mathrm{~km}$ (including the ground and underground river; Fig. 1). The southeastern portion of the basin is lower than the northwestern portion. The relative elevation of the basin is approximately $150 \mathrm{~m}$, and its average altitude is $1250 \mathrm{~m}$. A typical hoodoo depression physiognomy is distributed in the east of the basin, where the main land-use type is forest vegetation, while karst is distributed in the west of the basin where the main land-use type is farmland. The area has a subtropical humid climate; the average rainfall is $1316.8 \mathrm{~mm}$ and the average temperature is $15.5^{\circ} \mathrm{C}$. The wet season occurs from May to October, and the dry season from November to April. Precipitation during the wet season accounts for more than $80 \%$ of annual rainfall. Bedrock in the basin is composed of mainly carbonate rock formed during the Triassic. As a result of lithology and geological structure, karstification is strong, 
and karst formation is widely developed in the basin. Hydrological run-off processes are significantly influenced by the karst underground space (gap and pipe) and its distribution characteristics. There is no obvious surface river valley upstream, and although there is a river valley midstream and downstream, seasonal run-off only appears temporarily, and leakage pits are arranged along the riverbed.

\subsection{Data sources and methods}

\subsubsection{Data sources}

The main data were derived from three hydrological stations (monitoring the flow and concentration of ions in water): Maoshuikeng (MSK), Liugu (LG), and Laoheitan (LHT), represented by the letters A, B, and C in Fig. 1, respectively. The MSK station is located at the outlet of the underground river (downstream), and its control area is $80.56 \mathrm{~km}^{2}$. The LHT station is located on the edge of the peak cluster depression (upstream), and the LG station is located in the region of the peak cluster basin (midstream). Control areas of the two stations are 24.06 and $15.81 \mathrm{~km}^{2}$, respectively (Wang et al., 2010). We selected continuous and complete data, which contain average daily flow data and $\mathrm{HCO}_{3}^{-}$concentration data from the MSK station (1996-2001), LG station (19921996), and LHT station (1988-2002). The average annual temperatures from 1988 to 2002 were calculated from temperatures recorded by the Puding station, which is located at the boundary of the basin. Concentration data were measured directly by the water sampling station. Water samples were collected from the underground rivers at a water depth of $0.6 \mathrm{~m}$ at the exit, six times per month in the wet season (May to October) and three times per month in the dry season (November to April of the following year), and water samples were measured for $\mathrm{pH}$ using a portable meter. The water temperature and concentration of bicarbonate $\left(\left[\mathrm{HCO}_{3}^{-}\right]\right)$ were determined by titration with standard hydrochloric acid $(\mathrm{HCl})$ immediately after samples were collected at the sampling site.

\subsubsection{Determination of water samples and DIC method}

Bicarbonate concentration was measured using a neutralization titration method. The steps of the method are as follows: (1) add a sample to a $100 \mathrm{~mL}$ beaker, drip four drops of phenol red indicator into the sample, and shake well; (2) titrate the sample using $\mathrm{HCl}\left(0.025 \mathrm{~mol} \mathrm{~L}^{-1}\right)$ until the red colour disappears at a $\mathrm{pH}$ of 8.4 and record the $\mathrm{HCl}\left(0.025 \mathrm{~mol} \mathrm{~L}^{-1}\right)$ usage quantity as V1; (3) drip three drops of methyl orange indicator into the sample and shake well, then titrate using $\mathrm{HCl}\left(0.025 \mathrm{~mol} \mathrm{~L}^{-1}\right)$ until the colour of the sample changes to orange at a $\mathrm{pH}$ of 4.4 , and record the $\mathrm{HCl}$ usage quantity (V2); and (4) finally, measure the concentration of carbonate ions in the water samples by using Eq. (1):

$\rho=\frac{\left(V_{2}-V_{1}\right) \times c \times 61.017 \times 1000}{V}$.

The flow discharge data of each station were converted from the water level using a stage-discharge curve. The discharge monitoring frequency was twice a day, with eight points in the morning and eight points in the evening, and the average value of the two time periods was calculated as the discharge data for 1 day.

In a karst environment, carbon dioxide dissolves in water and undergoes a reversible chemical process (2) with calcium carbonate:

$\mathrm{CaCO}_{3}+\mathrm{H}_{2} \mathrm{O}+\mathrm{CO}_{2} \Leftrightarrow \mathrm{Ca}^{2+}+2 \mathrm{HCO}_{3}^{-}$.

Under a steady state, the quantity of carbon dioxide dissolved in karst water is equal to the discharge of $\mathrm{CO}_{2}$ from the atmosphere. That discharge in a $\mathrm{g} \mathrm{C} \mathrm{m}^{-2}$ time step ${ }^{-1}$ is calculated according to the following Eq. (3) (Yan et al., 2011; AmiotteSuchet and Probst, 1993):

$F=\frac{1}{2} c q \frac{M_{c}}{M_{\mathrm{HCO}_{3}}}$,

where $c$ is the concentration of bicarbonate ions $\left(\mathrm{g} \mathrm{m}^{-3}\right)$; $q$ is the production flow $\left(\mathrm{m}^{3}\right.$ time step $\left.{ }^{-1}\right) ; M_{c}$ and $M_{\mathrm{HCO}_{3}}$ $M_{\mathrm{HCO}_{3}}$ are the molecular weights of $\mathrm{C}$ and $\mathrm{HCO}_{3}^{-}$, respectively; and $1 / 2$ indicates that $1 \mathrm{~mol}$ of bicarbonate only needs half a mole of $\mathrm{CO}_{2}$ from the soil or atmosphere. Additionally, karst water is generally alkaline. The content of $\mathrm{CO}_{3}^{2-} \mathrm{C}$ in dissolved inorganic $\mathrm{C}$ is very small, so we did not need to consider it in the DIC calculation (Yan et al., 2011; Gelbrecht et al., 1998). In this study, we used the formula $F_{1}$ below to calculate net carbon uptake by karst, using the estimates of mean annual $\left[\mathrm{HCO}^{-}\right]$, ion concentration during the dry-wet season, and the mean daily underground flow discharge.

$F_{1}=\frac{1}{2} \cdot \frac{M_{c}}{M_{\mathrm{HCO}_{3}}} \cdot \bar{c} \cdot \sum_{n=1}^{12} q_{n}$,

where $\bar{c}$ is either the annual average bicarbonate density or the ion concentration in the dry-wet season $\left(\mathrm{mg} \mathrm{L}^{-1}\right)$, and $q$ is the average daily discharge $\left(\mathrm{m}^{3} \mathrm{~s}^{-1}, n=365\right.$ day).

\section{Results}

\subsection{Dry-wet seasonal and inter-annual variations in ion concentration and discharge}

There was a negative correlation between ion concentration and discharge (Figs. 2, 3, and 4). During the study period, the ion concentration in the wet season was slightly lower than in the dry season at each site. The LHT station, which had the longest study period, exhibited the highest and lowest 

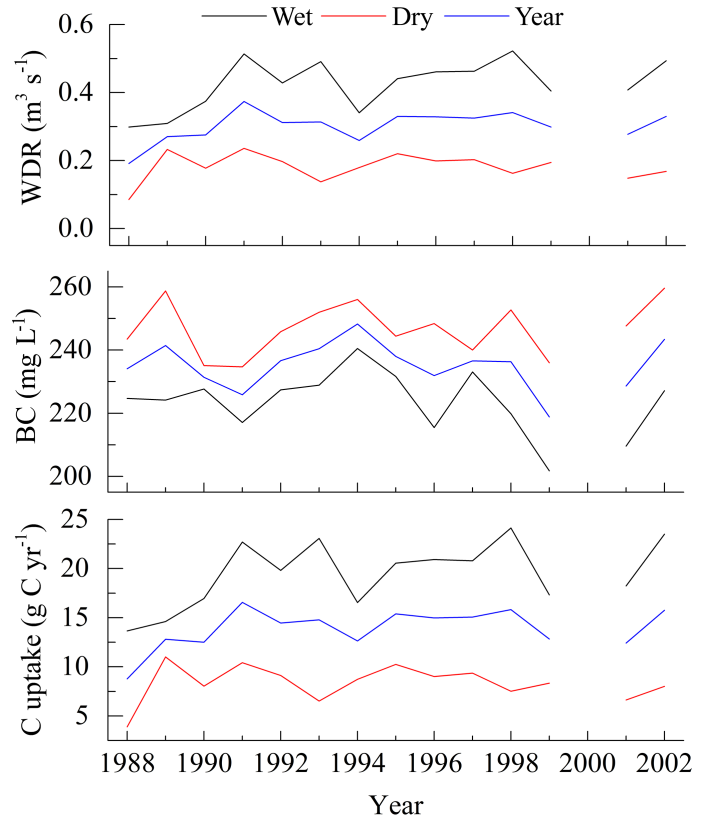

Figure 2. Variation in run-off, ion concentration, and carbon sink for the LHT station (1988-2002).

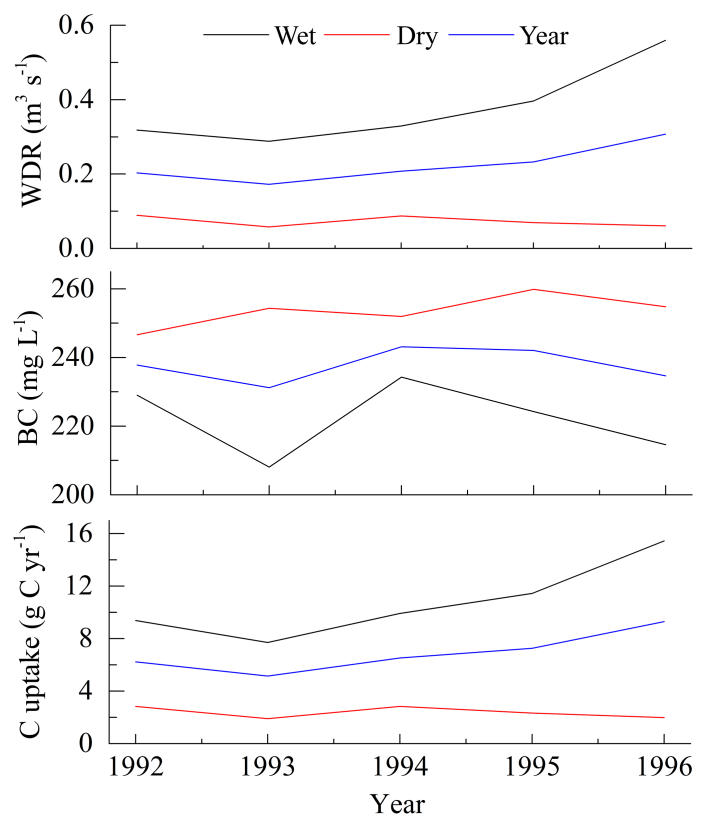

Figure 3. Variation in run-off, ion concentration, and carbon sink for the LG station (1992-1996).

values for bicarbonate ion concentration (Table 2), and the difference in the ion concentration between wet season and dry season was not significant. The flow, ion concentration, and carbon flux data of 2001 from LHT were missing, and we therefore replaced them with the data of 2002 in the paper.
The annual average ion concentration recorded at the LG station was more stable than at the LHT station. From 1992 to 1996 , the annual average concentration of bicarbonate ions in the wet season, dry season, and whole year were 222.0, 253.5 , and $237.8 \mathrm{mg} \mathrm{L}^{-1}$, respectively at the $\mathrm{LG}$ station and $228.8,249.3$, and $239.1 \mathrm{mg} \mathrm{L}^{-1}$, respectively at the LHT station. However, there was little difference in ion concentration between the two stations when considering the stability of ion concentration changes (Table 3 ).

The differences in ion concentration measured at all considered stations as a whole were small. The annual average ion concentrations measured at the MSK station were more stable than those at the LHT station with respect to the standard deviation of the ion concentration (Table 3). During the same period, i.e. from 1996 to 2001, the annual average ion concentrations in the wet season, dry season, and whole year were $217.8,247.4$, and $232.6 \mathrm{mg} \mathrm{L}^{-1}$, respectively at the LHT station, and 209.9, 226.4, and $218.2 \mathrm{mg} \mathrm{L}^{-1}$, respectively at the MSK station. The difference in ion concentration between LHT and LG was smaller than that between LHT and MSK.

The flow in the wet season was significantly greater than in the dry season. The discharge from the MSK station, which is located at the outlet of the underground river basin, was larger than that from LG and LHT. From 1996 to 2001, the annual average flow values of MSK in the wet season, dry season, and whole year were $1.55,0.67$, and $1.11 \mathrm{~m}^{3} \mathrm{~s}^{-1}$, respectively. The LG and LHT flows in the wet and dry seasons exhibited the same trend (Figs. 2, 3, and 4). From Table 3, we can determine the stability of flow as follows: MSK $>$ LG $>$ LHT.

\subsection{Dry and wet seasonal and inter-annual variations in carbon uptake rate}

There was a significantly larger discharge in the wet season compared to that in the dry season. From 1996 to 2001 at the MSK station, the annual average carbon sink discharges of underground water in the wet season, dry season, and whole year were $12.51,5.78$, and $9.28 \mathrm{~g} \mathrm{C} \mathrm{m}^{-2} \mathrm{yr}^{-1}$, respectively. From 1992 to 1996 at the LG station, the annual average carbon sink discharges in the wet season, dry season, and whole year were 10.78, 2.38, and $6.89 \mathrm{~g} \mathrm{C} \mathrm{m}^{-2} \mathrm{yr}^{-1}$, respectively. From 1988 to 2002 at the LHT station, the annual average carbon sink discharges in the wet season, dry season, and whole year were 19.48, 8.34, and $13.91 \mathrm{~g} \mathrm{C} \mathrm{m}^{-2} \mathrm{yr}^{-1}$, respectively, which were larger than those at the LG and MSK stations (Fig. 6). From 1996 to 2002 at the LHT station, the annual average net carbon sink discharges in the wet season, dry season, and whole year were $20.82,8.14$, and $14.48 \mathrm{~g} \mathrm{C} \mathrm{m}^{-2} \mathrm{yr}^{-1}$, respectively, while from 1992 to 1996 the respective values were 20.18, 8.72 , and $14.45 \mathrm{~g} \mathrm{C} \mathrm{m}^{-2} \mathrm{yr}^{-1}$. Compared to the results for the same period, the annual carbon sink discharges in the wet season, dry season, and whole year for the LHT station were 


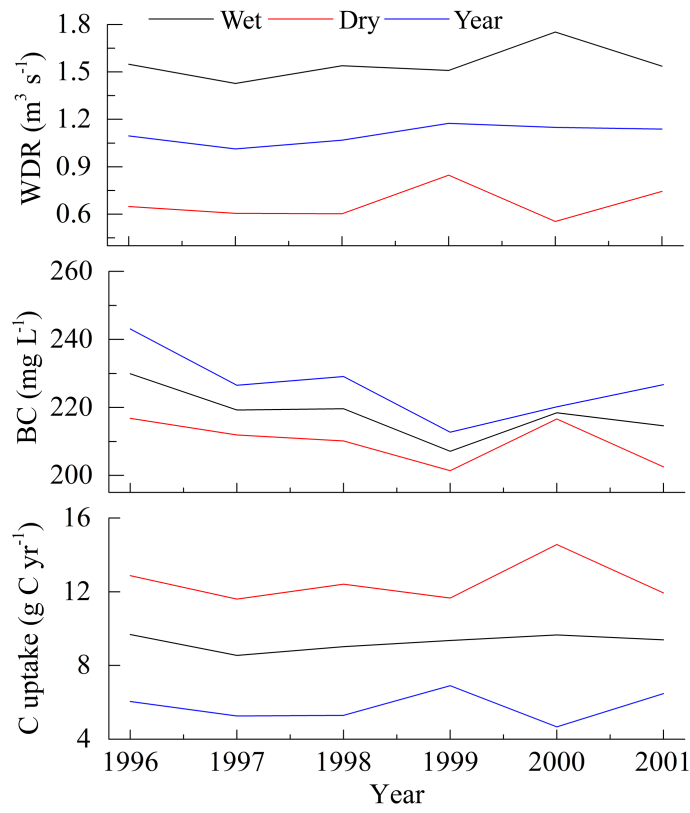

Figure 4. Variation in run-off, ion concentration, and carbon sink for the MSK station (1996-2001).

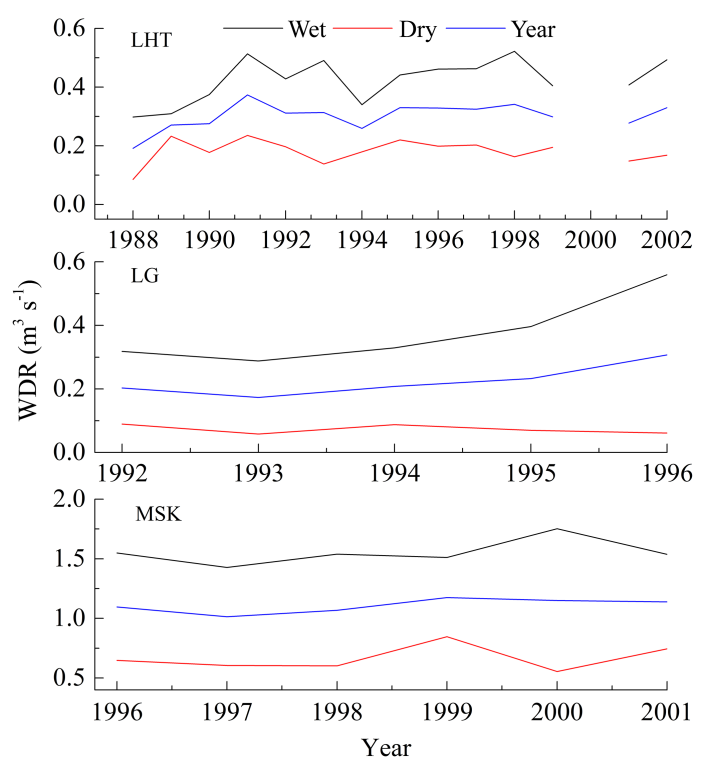

Figure 5. Variation in flow among sites in the wet season, dry season, and whole year during the study period.

greater than those for the MSK and LG stations. However, with respect to the stability of the carbon discharge (Table 3), MSK's was the most stable in the wet season while LG's was the most stable in the dry season.

\section{Discussion}

\subsection{Flow and ion concentration change and their effects on carbon sink}

The trends in annual run-off among sites are consistent with the carbon sink discharge but differ from the trends of the bicarbonate ions (Figs. 2, 3, 4). This suggests that the effect of flow change on the carbon sink was greater than on the ion concentration. The flow in the wet season was consistent with the flow trend for the whole year. This is a result of the monsoon climate, when wet season precipitation levels are significantly higher than in the dry season, due to less rainfall in the dry season when the run-off is mainly supplied by soil water and fissure/porewater. Therefore, the composition of underground karst aquifer medium structures has important effects on the dry season flow. According to changes in ion concentration in the wet season, dry season, and whole year (Figs. 2, 3, and 4), flow correlated negatively with the carbon ion concentration, but if there were a significant difference between the flow in the wet season and in the dry season, the bicarbonate ion concentrations would not decrease when the flow increased rapidly.

Although the ion concentrations were higher in the dry season than in the wet season, the differences were small. When there was little change in flow, the effect of flow increase on the ion concentration dilution was smaller than the environmental effect of chemical carbonate weathering. Contrasts were made between each site: from 1992 to 1996, the annual average carbon ion concentrations were $237.8 \mathrm{mg} \mathrm{L}^{-1}$ at the LG station and $239.1 \mathrm{mg} \mathrm{L}^{-1}$ at the LHT station. The annual average flow of the LHT station was 1.37 times as high as that of the LG station, but the ion concentration did not decline significantly due to the increase in flow. The basin area controlled by the LHT station is characterized by peaks and valleys that have a rapid recovery of good vegetation cover. Previous studies have shown that the concentration of $\mathrm{HCO}_{3}^{-}$is vulnerable to Land-Use and Cover-Change (LUCC) and other environmental changes (Zhao et al., 2010; Lan et al., 2015). In particular, the rapid recovery of vegetation can significantly promote the dissolution of carbonate and thus increase the bicarbonate ion concentration in karst groundwater (Berner, 1997; Liu et al., 2010).

The flow only had a partial dilution effect on the ion concentration, and the results were not multiplicative; that is to say, carbonate weathering was significantly affected by factors other than flow. This also implies that the bicarbonate ion concentrations in the karst underground water may have a relatively stable extremum under stable environmental conditions. From 1996 to 2001, the annual average carbon ion concentrations at the LHT and MSK stations were 232.6 and $218.2 \mathrm{mg} \mathrm{L}^{-1}$, respectively, but the average annual flow at LHT was only $0.32 \mathrm{~m}^{3} \mathrm{~s}^{-1}$, while MSK exhibited an annual flow of $1.11 \mathrm{~m}^{3} \mathrm{~s}^{-1}$, i.e. 3.47 -fold higher. Similarly, the ion concentration did not decline significantly as a result of the 


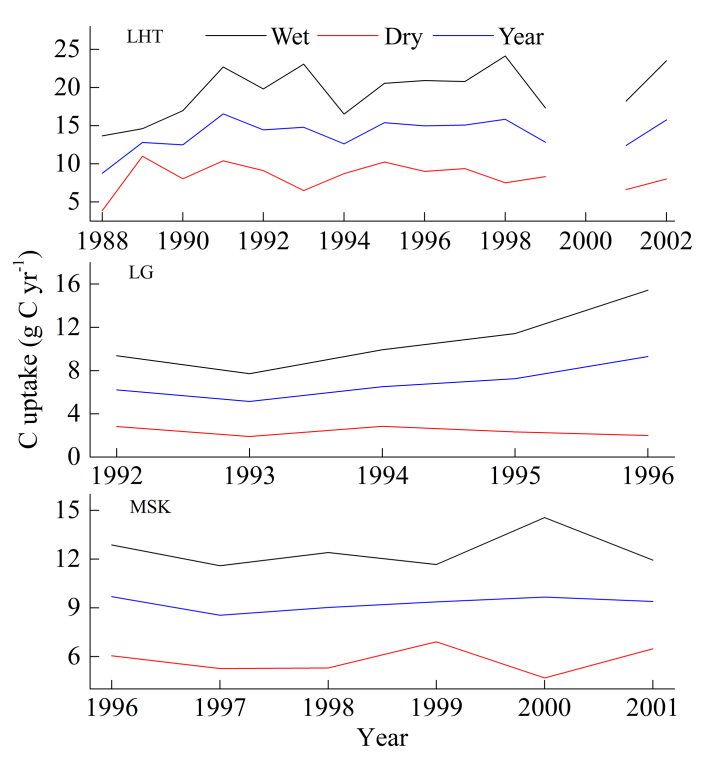

Figure 6. Variation in net carbon discharge among sites in the wet season, dry season, and whole year during the study period.

increase in flow. The MSK station is located at the edge of a paddy field, where the soil coverage is thicker, and the underground rivers have more biological carbon sources that could produce more $\mathrm{HCO}_{3}^{-}$in the groundwater compared to at the LHT. The effect of the flow increase on the ion concentration dilution exceeded the environmental effects of carbonate weathering at the LHT and MSK stations.

In addition, although studies have shown that under stable LUCC conditions, the strength of the carbon sink from rock weathering will depend on the climate (e.g. temperature, Hagedorn and Cartwright, 2009; Gislason et al., 2009; Tipper et al., 2006), the trend of annual average carbon sink at the LHT station, which had the longest study period data (1988-2002), differed significantly from the annual average temperature trend. However, this may be a result of time resolution limitations of the data.

\subsection{Variation in carbon sink discharge for each site}

The karst carbon sink changed significantly with the seasons, exhibiting striking seasonal patterns. The carbon sink discharge for each site in the wet season was greater than in the dry season and the whole year, while the carbon sink discharge in the dry season was lower than that of the annual average (Fig. 6). The reason is that the amount of carbon sink discharge in the wet season was increased significantly because of the considerable summer rainfall run-off.

The difference in carbon sink discharges between the LHT and LG stations resulted from differences among flows. During the same period, the carbon sink values at the LHT station (wet season, dry season, and whole year) were greater than those at LG stations (Fig. 6). From 1992 to 1996, the

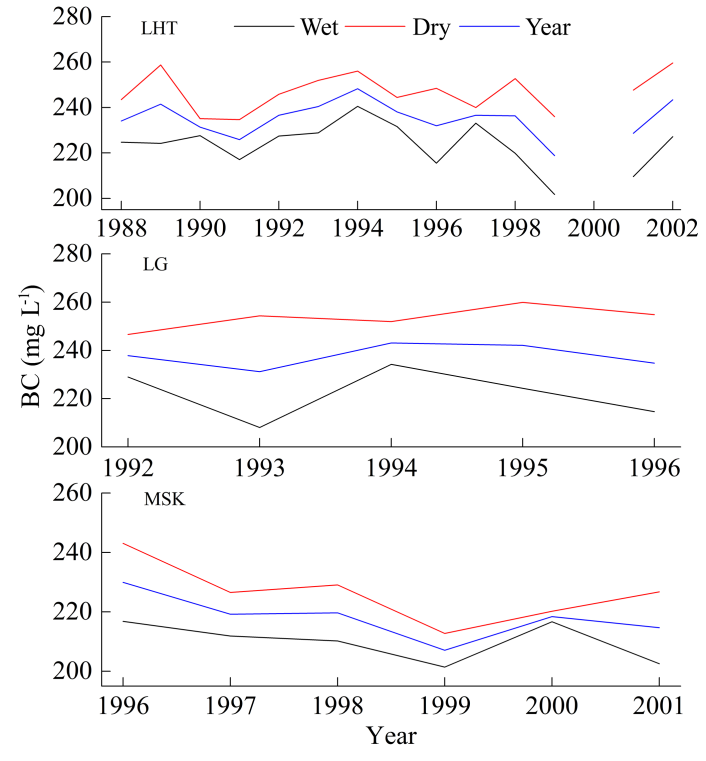

Figure 7. Variation in bicarbonate ion concentrations among sites in the wet season, dry season, and whole year during the study period.

flow of LG in the wet and dry seasons was lower than of LHT (Fig. 5), but the annual average bicarbonate concentration of LG was $237.8 \mathrm{mg} \mathrm{L}^{-1}$, slightly less than of LHT (239.1 $\mathrm{mg} \mathrm{L}^{-1}$; Fig. 7). Differences of carbon sink discharge between two stations may be further increased due to different LUCC types. The LHT control basin station is mainly surrounded by forest vegetation, while the LG control basin is mainly surrounded by dry farmland.

From 1996 to 2001, the carbon sink for the LHT station in the dry and wet seasons and whole year was greater than for the MSK station (Fig. 6). The annual average concentration for LHT $\left(232.6 \mathrm{mg} \mathrm{L}^{-1}\right)$ was greater than for MSK (218.2 $\mathrm{mg} \mathrm{L}^{-1}$ ), while the run-off for MSK was significantly greater than for LHT (Fig. 7). We hypothesize that the above results are caused by two main reasons as follows. On the one hand, the fact that the carbon sink for MSK was less than that for LHT might be linked to the water conveyance distance and LUCC type of the control area. The carbon sink for MSK, which is the groundwater outlet for the whole basin, was influenced by the landform and LUCC type of the entire river basin. Existing research has shown that karst erosion rates under soil vary significantly for different LUCC types in karst watersheds, and the averages for cultivated land, thickets, secondary forests, grassland, and forest were found to be $4.02,7.0,40.0,20.0$, and $63.5 \mathrm{t} \mathrm{km}^{2} \mathrm{a}^{-1}$, respectively (Zhang, 2011), among which the cultivated land value was the lowest (Yan et al., 2014). Forest trees have a significant promoting effect on carbonate weathering of carbonate rocks (Thorley et al., 2015). Vegetation can increase the speed of rock weathering by 3-10-fold (Berner, 1997). According to monitoring data from Guilin in southwestern China, vegetation restoration resulted in a $266 \%$ increase in the average an- 
nual concentration of soil $\mathrm{CO}_{2}$ over 10 years. Research in the Houzhai valley has shown that forest recovery causes more carbon dioxide $\left(\mathrm{CO}_{2}\right)$ to be dissolved in karst water (Yan et al., 2014), and karst hydrogeochemistry and the karstrelated carbon cycle could be regulated effectively by different LUCC types (Zhao et al., 2010; Calmels et al., 2014).

On the other hand, in the process of underground run-off converging at the outlet (MSK station), large amounts of water flow into the surface river and across the thick soil of paddy fields, but only the carbonate weathering carbon sinks (water-rock-gas interaction) were considered in our calculation, which may affect the results. Research has shown that dissolved inorganic carbon is used in aquatic photosynthesis for the synthesis of organic carbon (Waterson and Canuel, 2008; Tao et al., 2009). In addition, the precipitation recharge coefficients of MSK, LG, and LHT were 0.485, 0.503 and 0.503 , respectively (Chen et al., 2014). The groundwater quantity is determined by the difference in the precipitation recharge coefficient for the basin under the same rainfall conditions, and the development degree of the underground pipe network also influences the water-rock contact time. Differences in surface and groundwater proportions controlled by geological landforms could also affect the calculation results.

\section{Conclusion and suggestions}

Based on the analysis of the three stations located upstream, midstream, and downstream of the Houzhai Basin, we analysed the reasons for the differences in flow, bicarbonate ion concentrations, and carbon sink discharge. The preliminary conclusions are as follows. (1) The carbon sink discharge was mainly controlled by the flow of each site, and LUCC type had important effects on the bicarbonate ion concentrations at each site. (2) The huge difference in flow among sites did not lead to significant differences in bicarbonate ion concentrations between the sites, showing that the rapid increase in flow only had a partial dilution effect on the ion concentrations. Due to the high speed and stability of chemical carbonate weathering, the bicarbonate ion concentrations did not change significantly, and thus did not affect the carbon sink discharge. (3) Under the different LUCC conditions, if the run-off is stable, the influence of flow variation on ion concentration will be less than the effects of chemical carbonate weathering on bicarbonate ion concentrations caused by different environmental conditions (a comparison of LHT and LG showed a difference of $150 \%$ ). However, if run-off increases significantly, the impact of run-off variation on bicarbonate ions will be greater than the effects of chemical carbonate weathering caused by different environmental conditions (comparison results of LHT and MSK).

In summary, the calculation results of carbon sink discharge from karstification using watershed monitoring data in areas restricted to a dominant single LUCC type may differ in a small watershed where geomorphology, hydrology, and land-use cover are different. This is one of the reasons that there is such a large deviation in China's total carbon sink discharge estimated using carbon sink data from a single watershed in a karst region. In future research, considering the diversity of landform types and surface covers in the southwestern karst area, it is important to develop a monitoring network in different topographical and surface cover regions, using a variety of monitoring technologies to improve the accuracy of karst carbon sink estimates.

In addition, we could not properly quantify the impacts of vegetation and other factors on the karst carbon sink in the research basin because the data used in the study did not have a high temporal resolution. At the same time, the data failed to provide a quantitative conclusion. However, based on the purpose of this paper, the existing data can meet the needs of the analysis, so as to draw a qualitative research conclusion. From the point of view of research and development in the future, high temporal resolution monitoring acquired by automatic monitoring equipment should be the basis for quantitative studies on vegetation and other factors that impact the karst carbon sink; this may help to reduce uncertainty errors and is our main direction of research in the future.

\section{Data availability}

The data are acquired from Puding Karst Ecological Comprehensive Research Station.

Acknowledgements. This work was partially supported by the National Natural Science Foundation of China (no. 41371045 and no. 41261038), the National Social Science Foundation of China (no. 13CJY067), and the National Key Technology R\&D Program of China (no. 2014BAB03B001).

Edited by: A. Jordán

Reviewed by: M. Oliva and two anonymous referees

\section{References}

Amiotte-Suchet, P. and Probst, J.: $\mathrm{CO}_{2}$ flux consumed by chemicalweathering of continents-influences of drainage and lithology, Comptes Rendus De L Academie Des Sciences Serie II, 317, 615-622, 1993.

Baldini, J. U., Baldini, L. M., McDermott, F., and Clipson, N.: Carbon dioxide sources, sinks, and spatial variability in shallow temperate zone caves: evidence from Ballynamintra Cave, Ireland, J. Cave Karst Stud., 68, 4-11, 2006.

Berner, R. A.: The Rise of Plants and Their Effect on Weathering and Atmospheric $\mathrm{CO}_{2}$, Science, 276, 544-546, 1997.

Berner, R., Lasaga, A., and Garrels, R.: The carbonate-silicate geochemical cycle and its effect on atmospheric carbon dioxide over the past 100 million years, Am. J. Sci., 283, 641-683, 1983.

Bluth, G. J. S. and Kump, L. R.: Lithologic and climatologic controls of river chemistry, Geochim. Cosmochim. Ac., 58, 23412359, 1994. 
Calmels, D., Gaillardet, J., and François, L.: Sensitivity of carbonate weathering to soil $\mathrm{CO}_{2}$ production by biological activity along a temperate climate transect, Chem. Geol., 390, 74-86, 2014.

Chen, B., Yang, R., Liu, Z., Yan, H., and Zhao, M.: Effects of aquatic phototrophs on diurnal hydrochemical and?13CDIC variations in an epikarst spring and two spring-fed ponds of Laqiao, Maolan, SW China, Geochimica, 43, 375-385, 2014.

Chen, X., Zhang, Z., and Rong, L.: Water cycle process and its ecohydrological effect of karsts areas in southwest of China, Science Press, Beijing, 2014.

Dreybolt, W.: Processes in karst systems, Springer-Verlag, Berlin, 1988.

Dürr, H. H., Meybeck, M., and Dürr, S. H.: Lithologic composition of the Earth's continental surfaces derived from a new digital map emphasizing riverine material transfer, Global Biogeochem. Cy., 19, doi:10.1029/2005GB002515, 2005.

Gelbrecht, J., Fait, M., Dittrich, M., and Steinberg, C.: Use of GC and equilibrium calculations of $\mathrm{CO}_{2}$ saturation index to indicate whether freshwater bodies in north-eastern Germany are net sources or sinks for atmospheric $\mathrm{CO}_{2}$, Fresenius', J. Anal. Chem. 361, 47-53, 1998.

Gislason, S. R., Oelkers, E. H., Eiriksdottir, E. S., Kardjilov, M. I., Gisladottir, G., Sigfusson, B,. Snorrason, A., Elefsen, S., Hardardottir, J., Torssander, P., and Oskarsson, N.: Direct evidence of the feedback between climate and weathering, Earth Planet. Sc. Lett., 277, 213-222, 2009.

Hagedorn, B. and Cartwright, I.: Climatic and lithologic controls on the temporal and spatial variability of $\mathrm{CO}_{2}$ consumption via chemical weathering: An example from the Australian Victorian Alps, Chem. Geol., 260, 234-253, 2009.

Hoffmann, T., Mudd, S. M., Van Oost, K., Verstraeten, G., Erkens, G., Lang, A., Middelkoop, H., Boyle, J., Kaplan, J. O., Willenbring, J., and Aalto, R.: Short Communication: Humans and the missing C-sink: erosion and burial of soil carbon through time, Earth Surface Dynam., 1, 45-52, 2013.

Huang, F., Zhang, C., Xie, Y., Li, L., and Cao, J.: Inorganic carbon flux and its source in the karst catchment of Maocun, Guilin, China, Environ. Earth Sci., 74, 1079-1089, 2015.

Jiang, Z. C., Lian, Y. Q., and Qin, X. Q.: Rocky desertification in Southwest China: Impacts, causes, and restoration, Earth-Sci. Rev., 132, 1-12, 2014.

Jiang, Z. C. and Yuan, D. X.: $\mathrm{CO}_{2}$ source-sink in karst processes in karst areas of China, Episodes, 21, 33-35, 1999.

Kang, Z., Yuan, D., Chang, Y., Li, Q., He, S., Yan, Y., and Xiong, Z.: The Main Controlling Factor of Karst Carbon Sequestration: About Water Cycle, Journal of Jilin University, Earth Science Edition, 41, 1542-1547, 2011.

Kao, S. J., Hilton, R. G., Selvaraj, K., Dai, M., Zehetner, F., Huang, J. C., Hsu, S. C., Sparkes, R., Liu, J. T., Lee, T. Y., Yang, J. Y. T., Galy, A., Xu, X., and Hovius, N.: Preservation of terrestrial organic carbon in marine sediments offshore Taiwan: mountain building and atmospheric carbon dioxide sequestration, Earth Surf. Dynam., 2, 127-139, 2014.

Lan, F., Qin, X., Jiang, Z., Meng, R., Mo, R., Yang, S., Wang, W., and An, S.: Influences of Land Use/Land Cover on Hydrogeochemical Indexes of Karst Groundwater in the Dagouhe Basin, Southwest China, Clean-Soil, Air, Water, 43, 683-689, 2015.
Lian, B., Yuan, D. X., and Liu, Z. H.: Effect of microbes on karstification in karst ecosystems, Chinese Science Bulletin, 56, 21582161, 2011.

Liu, L., Shu, L., Chen, X., and Oromo, T.: The hydrologic function and behavior of the Houzhai underground river basin, Guizhou Province, southwestern China, Hydrogeol. J., 18, 509-518, 2010.

Liu, Y., Liu, Z., Zhang, J., He, Y., and Sun, H.: Experimental study on the utilization of DIC by Oocystis solitaria Wittr and its influence on the precipitation of calcium carbonate in karst and non-karst waters, Carbonate. Evaporite., 25, 21-26, 2010.

Liu, Z.: New progress and prospects in the study of rockweathering-related carbon sinks, Chinese Sci. Bull., 57, 95-102, 2012.

Liu, Z. and Zhao, J.: Contribution of carbonate rock weathering to the atmospheric $\mathrm{CO}_{2}$ sink, Environ. Geol., 33, 1053-1058, 2000.

Melnikov, N. B. and Neill, B. C. O.: Learning about the carbon cycle from global budget data, Geophys. Res. Lett., 33, doi:10.1029/2005GL023935, 2006.

Passow, U. and Carlson, C. A.: The biological pump in a high $\mathrm{CO}_{2}$ in world, Mar. Ecol.-Prog. Ser., 470, 249-271, 2012.

Qin, X., Meng, R., and Mo, R.: Influence of land covers on carbon sink of underground river: A case in the Dagouhe Basin in Guangxi, Carsologica Sinica, 30, 372-378, 2011.

Schindler, D. W.: The mysterious missing sink, Nature, 398, 105107, 1999.

Serrano-Ortiz, P., Roland, M., Sanchez-Moral, S., Janssens, I. A., Domingo, F., Godderis, Y., and Kowalski, A. S.: Hidden, abiotic $\mathrm{CO}_{2}$ flows and gaseous reservoirs in the terrestrial carbon cycle: Review and perspectives, Agr. Forest Meteorol., 150, 321-329, 2010.

Tao, F. X., Liu, C. Q., and Li, S. L.: Source and flux of POC in two subtropical karstic tributaries with contrasting land use practice in the Yangtze River Basin, Appl. Geochem., 24, 2102-2112, 2009.

Thorley, R. M. S., Taylor, L. L., Banwart, S. A., Leake, J. R., and Beerling, D. J.: The role of forest trees and their mycorrhizal fungi in carbonate rock weathering and its significance for global carbon cycling, Plant Cell Environ., 38, 1947-1961, 2015.

Tipper, E. T., Bickle, M. J., Galy, A., West, A. J., Pomiè, C., and Chapman, H. J.: The short term climatic sensitivity of carbonate and silicate weathering fluxes: Insight from seasonal variations in river chemistry, Geochim. Cosmochim. Ac., 70, 2737-2754, 2006.

Wan, G.: Carbonate and environment, Volume 1, Seismological Press, Beijing, 1995.

Wang, L., Meng, H., Zhang, Z., and Wang, D.: Study on the hydrology and water resources of the typical karst basin in Guizhou, Science Press, Beijing, 2010.

Waterson, E. J. and Canuel, E. A.: Sources of sedimentary organic matter in the Mississippi River and adjacent Gulf of Mexico as revealed by lipid biomarker and $\delta 13 \mathrm{CTOC}$ analyses, Org. Geochem., 39, 422-439, 2008.

Yan, J., Li, J.,Ye, Q., and Li, K.: Concentrations and exports of solutes from surface runoff in Houzhai Karst Basin, southwest China, Chem. Geol., 304-305, 1-9, 2012.

Yan, J., Wang, W.,Zhou, C., Li, K., and Wang, S.: Responses of water yield and dissolved inorganic carbon export to forest recovery in the Houzhai karst basin, southwest China, Hydrol. Process., 28, 2082-2090, 2014. 
Yan, J., Wang, Y. P., Zhou, G., Li, S., Yu, G., and Li, K.: Carbon uptake by karsts in the Houzhai Basin, southwest China, J. Geophys. Res., 116, doi:10.1029/2011JG001686, 2011.

Yu, S., Du, W., Sun, P., Huang, J., Luo, H., Li, Y., and He, S.: Study on Chemical Characteristics, Carbon Flux and Influencing Factors of Typical Rivers in Subtropics, J. China Hydrol., 35, 33-41, 2015.

Yuan, D. X.: Sensitivity of karst process to environmental change along the PEP II transect, Quatern. Int., 37, 105-113, 1997.

Zeng, C., Liu, Z., Yang, J., and Yang, R.: A groundwater conceptual model and karst-related carbon sink for a glacierized alpine karst aquifer, Southwestern China, J. Hydrol., 529, 120-133, 2015.

Zhang, C.: Carbonate rock dissolution rates in different landuses and their carbon sink effect, Chinese Sci. Bull., 56, 2174-2180, 2011.

Zhang, J. Y., Dai, M. H., Wang, L. C., Zeng, C. F., and Su, W. C.: The challenge and future of rocky desertification control in karst areas in southwest China, Solid Earth, 7, 83-91, doi:10.5194/se7-83-2016, 2016.
Zhang, L., Qin, X., Liu, P., Huang, Q., Lan, F., and Ji, H.: Estimation of carbon sink fluxes in the Pearl River basin (China) based on a water-rock-gas-organism interaction model, Environ. Earth Sci., 74, 945-952, 2015.

Zhao, M., Zeng, C., Liu, Z. H., and Wang, S. J.: Effect of different land use/land cover on karst hydrogeochemistry: A paired catchment study of Chenqi and Dengzhanhe, Puding, Guizhou, SW China, J. Hydrol., 388, 121-130, 2010. 